\title{
Approaches and challenges in supporting mathematics teachers' change
}

\author{
Olive Chapman ${ }^{1}$
}

Published online: 11 January 2016

(C) Springer Science+Business Media Dordrecht 2016

Special thanks to Dr. João Pedro da Ponte (Portugal) and Dr. Margaret Walshaw (New Zealand) for their invaluable service as Associate Editors of the Journal of Mathematics Teacher Education [JMTE]. They have ended their terms in 2015. Welcome to the new Associate Editors to fill their positions, Dr. Kim Beswick (Australia) and Dr. Salvador Llinares (Spain). It is a pleasure and honor to have them join the editorial team.

\section{Introduction}

Research on mathematics teachers has grown significantly over the last two decades. The broad scope of studies has focused on understanding, enhancing, and/or developing their mathematics knowledge, beliefs/conceptions, and pedagogical knowledge for teaching mathematics. They have offered insights to enable mathematics teacher educators to help teachers to make changes to their thinking and practice toward current perspectives of mathematics education (e.g., National Council of Teachers of Mathematics [NCTM] 2000, 2014). But significant change continues to be a challenge for many teachers. Reasons for this are usually attributed to the problematic nature of change or teacher-related factors. But are approaches being used to facilitate change able to attend to the different aspects of practice in an un-fragmented way? For example, NCTM (2014) suggests that effective mathematics teaching practices require teachers to: implement tasks that promote reasoning and problem solving, use and connect mathematical representations, facilitate meaningful mathematical discourse, pose purposeful questions, build procedural fluency from conceptual understanding, support productive struggle in learning mathematics, and elicit and use evidence of student thinking. Studies tend to focus and provide

Olive Chapman

chapman@ucalgary.ca

1 University of Calgary, Calgary, Canada 
insights on one or two of these aspects of practice and successes in changing thinking and/ or practice in them. However, we need to also understand how to engage teachers in all of them so they could understand them as interconnected and not separate aspects of practice.

The articles in this issue of JMTE contribute meaningful insights to this ongoing endeavor to change mathematics teachers' practice. Stephen Hegedus, John Tapper, and Sara Dalton's study involves teachers learning a technology-enhanced algebra curriculum; Janette Bobis, Jennifer Way, Judy Anderson, and Andrew Martin's study involves teachers learning about student engagement; Ian Whitacre and Susan Nickerson's study involves teachers learning of fractions; and Hala Ghousseini and Patricio Herbst's study involves teachers learning about classroom mathematics discussions. Each provides a different focus for an approach to prospective or practising teachers' learning and implies some ongoing challenges in achieving change that are highlighted in this editorial.

\section{Approaches to impact change}

This section presents some key aspects of the four studies regarding the different approaches that were used to support practising or prospective teachers' learning and impact change in their thinking and practice.

Hegedus et al.'s approach involves helping teachers to use SimCalc as a replacement for a high school Algebra-2 curriculum. SimCalc is a technology-enhanced curriculum consisting of student-centered instructional practices. The authors explained that the SimCalc learning environment supports many of the approaches highlighted in current literature regarding effective teaching (e.g., group learning and active learning) and the SimCalc program supports the communication of ideas within and across groups. Their professional development meetings with the teachers occurred over six weeks and focused on how to implement the technology and the associated curriculum materials. They also presented several classroom videos of SimCalc being used and discussed types of student interactions, teacher responses, technology use, and question strategies enacted.

The participants, from six school districts, were high school Algebra-2 students (15-17 years old) and their teachers from 28 classrooms, randomly divided equally into a treatment and control group. The study investigated what teacher-related contextual factors can account for differences in student achievement regarding the Algebra- 2 content and what relationship do changes in teachers' instructional practices and mathematical focus have with changes in their students' achievement. Findings of the statistical study indicated that none of the traditional teacher-related factors (class size, years of teaching, qualifications, and time on content) predicted student achievement on core algebra skills and conceptual understanding. However, there were significant shifts in the SimCalc teachers' instructional practices compared with the control-group teachers. The practices and performance goals that focused more on communication of ideas and advanced mathematical thinking were significant predictors of student achievement.

Bobis et al.'s approach involves helping teachers to understand student engagement in mathematics classrooms and instruction to support it. The approach occurred over 10 weeks in the final term of the school year. Its focus was on challenging teachers' beliefs about teaching and learning regarding student engagement in mathematics. The mathematics educators' role was to support the teachers' knowledge development and stimulate reflection on their existing beliefs about student engagement through activities requiring collaboration, discussion, and argumentation. They also facilitated discussion of evidence- 
based teaching practices linked to enhanced student engagement in mathematics for the teachers to enact in their classrooms. The teachers were prompted to develop teaching goals that would target specific needs of their students and were aligned to particular aspects of engagement discussed in the workshops. Through a carefully structured process consisting of a series of prompts, they planned specific strategies to try in their classrooms.

The study explored the shifts in beliefs about student engagement in mathematics of three Grades 5 and 6 teachers who participated in the approach. It was framed in the literature that suggests three types of engagement (behavioral, cognitive, and emotional) and a related multidimensional framework that provides a means to organize academic motivation and engagement. Findings indicated that student engagement in mathematics received little consideration by the teachers prior to the intervention. The teachers initially considered observable behaviors to be suggestive of student engagement and viewed both mathematics ability and engagement as personal characteristics that were beyond a teacher's ability to control. Impact of the approach varied for each teacher with some or little shift in beliefs.

Whitacre and Nickerson's approach involves helping prospective teachers to develop number sense of fraction magnitude. The approach employed a local instruction theory they had previously developed with a focus on whole-number mental computation that was being extended to the rational-number domain in this study. Their decisions regarding tasks, number choices, and anticipated student reasoning used in the approach were framed by a transform perspective, parts perspective, reference point perspective, and components perspective. Learning activities included area and linear models of fractions involving comparison tasks, placement tasks on the number line, and particular sequencing of these and other tasks. Participants moved through a specific hypothetical learning trajectory focused on reasoning about fraction magnitude.

The study investigated the impact of the approach on the participants' fraction sense, in particular how does their reasoning about fraction comparisons change. The participants were seven prospective elementary teachers enrolled in the first mathematics content course on numbers and operations belonging to a four-course sequence for prospective elementary teachers. Results of the study indicated that their performance and flexibility in comparing fractions improved. Overall, they performed better on fraction comparison tasks, scoring on average nearly two more correct responses post-instruction versus preinstruction. They also used a wider variety of valid strategies to perform those comparisons, demonstrating improved flexibility in reasoning about fraction magnitude.

Ghousseini and Herbst's approach involves supporting prospective secondary mathematics teachers' learning of leading mathematics discussions. The approach was framed in a curricular perspective with four interrelated components which novice teachers are expected to develop during their teacher preparation and a pedagogical perspective with three pedagogies of practice. This resulted in an approach with three pedagogies of practice to teach the leading of discussions and develop the four curricular goals: (1) course instructors represent a classroom discussion with a warm up problem, (2) instructors and prospective teachers decompose and name aspects of the representation, and (3) prospective teachers approximate the work of leading a discussion in three ways including using a constructed classroom dialog between a teacher and students around a mathematical problem and leading a classroom discussion in their field placement.

The approach occurred in a secondary mathematics methods course with 23 prospective teachers and two teacher educators/instructors. The study investigated the position that deliberate use of different pedagogies of practice can more comprehensively 
provide prospective teachers with opportunities to learn about leading classroom mathematics discussions. Findings supported this position and highlighted opportunities the approach offered to the participants. For example, it enabled them to check the limits of their knowledge, to attend to some instructional moves and dispositions in leading discussions, and to develop a vision of leading discussions. In particular, the three pedagogies enabled them to engage in practices that organize and constitute discourse between teacher and students, to experience the interpersonal and disciplinary demands of classroom discussions, and to consider aspects of leading discussions from the teacher's vantage point.

\section{Challenges to impacting teacher change}

While not an explicit goal of the four articles, there are underlying implications regarding some of the challenges that persist or can be encountered in helping practising and prospective teachers to change or develop their knowledge for meaningful teaching of mathematics. The following are examples of this.

First, while an approach may result in changes intended, it may not result in replacing old ways of thinking and/or acting. For example, in Hegedus et al.'s study, while there were significant changes to the SimCalc teachers' practice, they continued to engage students in memorization of facts and a focus on procedural tasks. In Whitacre and Nickerson's study, participants' reasoning shifted from predominantly standard strategies to including nonstandard strategies by a relatively small margin.

Second, while an approach may facilitate change for some aspects of practice throughout the period of intervention, it may take longer for change in other aspects to emerge. For example, in Hegedus et al.'s study, it was during the last quarter of the intervention period that the SimCalc teachers began to focus more on reasoning across multiple representations and making connections or comparisons across two or more functions than the control-group teachers.

Third, while an approach may result in significant changes for some teachers, it may not for others. For example, in Bobis et al.'s study, in spite of initial similarities in the teachers' thinking and practice regarding student engagement, while one teacher made significant changes, the other two continued to define "engagement" in generic terms and made only superficial changes to their beliefs about student engagement. In Whitacre and Nickerson's study, while all of the participants developed improved fractions sense, for one participant there was "profound change" in flexibility while for the others the change involved an increase in the numbers of "Valid and Correct" responses and each adopting at least two new valid strategies for comparing fractions.

Finally, for prospective teachers, change may require complex approaches to address the multiple aspects of mathematics education. For example, Ghousseini and Herbst's study showed that using three pedagogies of practice provided the prospective teachers with varied opportunities to attend to the different aspects of the Framework for Learning to Teach [FLT], allowed them to revisit certain elements of the FLT in different ways and made additional aspects of practice available for their understanding and investigation than if they had used only one pedagogy. 


\section{Conclusion}

The four articles offer promising approaches to impact specific changes to varying degrees for teachers. They provide evidence of the nature of change that is possible with each of these approaches and offer mathematics teacher educators guidance in supporting practising and prospective teachers' learning and change. They also provide outcomes that have implications regarding the nature and challenges of change. We are reminded that for significant change to occur teachers have to recognize the need for them to change their thinking and teaching, to understand the difference between what they have been doing and what is being proposed to do, and to have the confidence to do it successfully. We are also reminded that an approach is likely to have different overall impact on instructional practices for each participating teacher and be limited by the focus on changing specific aspects of mathematics instruction instead of addressing the multiplicity of change required for teachers "to be skilled at using instructional practices that are effective in developing mathematics learning for all students" (NCTM, 2014, p. 4). Given that there is ongoing need for significant changes in the teaching and learning of mathematics, ongoing work to understand the relationship between approaches to teachers' learning and change is important in order to continue to improve both. These four articles also offer meaningful theoretical perspectives that can inform such work.

\section{References}

National Council of Teachers of Mathematics. (2000). Principles and standards for school mathematics. Reston, VA: Author.

National Council of Teachers of Mathematics (2014). Principles to Actions: Executive Summary. Downloaded June 19, 2014. http://www.nctm.org/uploadedFiles/Standards_and_Focal_Points/Principles_to_ Action/PtAExecutiveSummary.pdf. 